Power Plant Assessment Program,

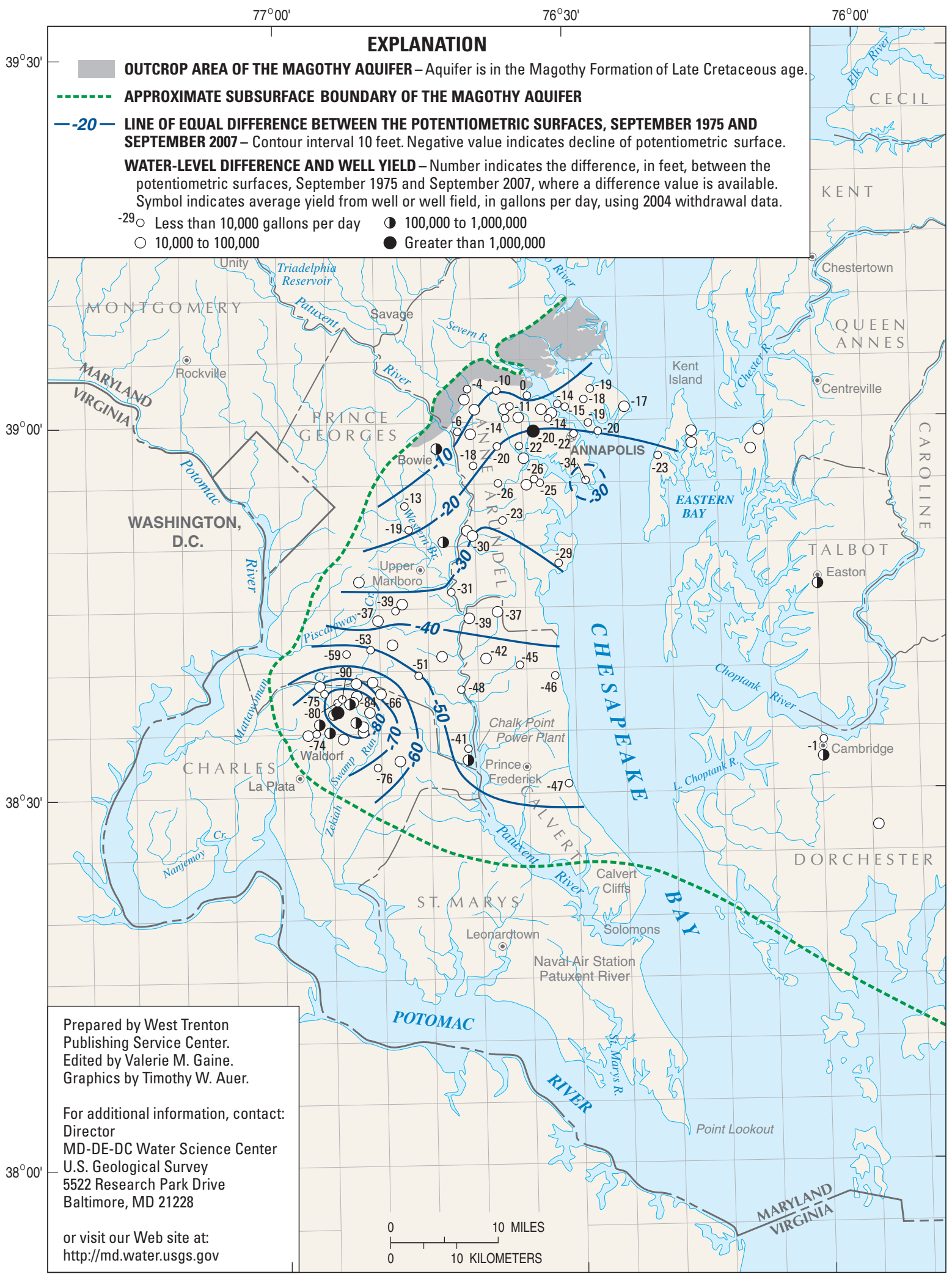

BASE FROM USGS DIGITAL LINE GRAPH, 1:250,000

\title{
The Difference Between the Potentiometric Surfaces of the Magothy Aquifer in Southern Maryland, September 1975 and September 2007
}

Stephen E. Curtin (USGS), David C. Andreasen (MGS), and Andrew W. Staley (MGS) 